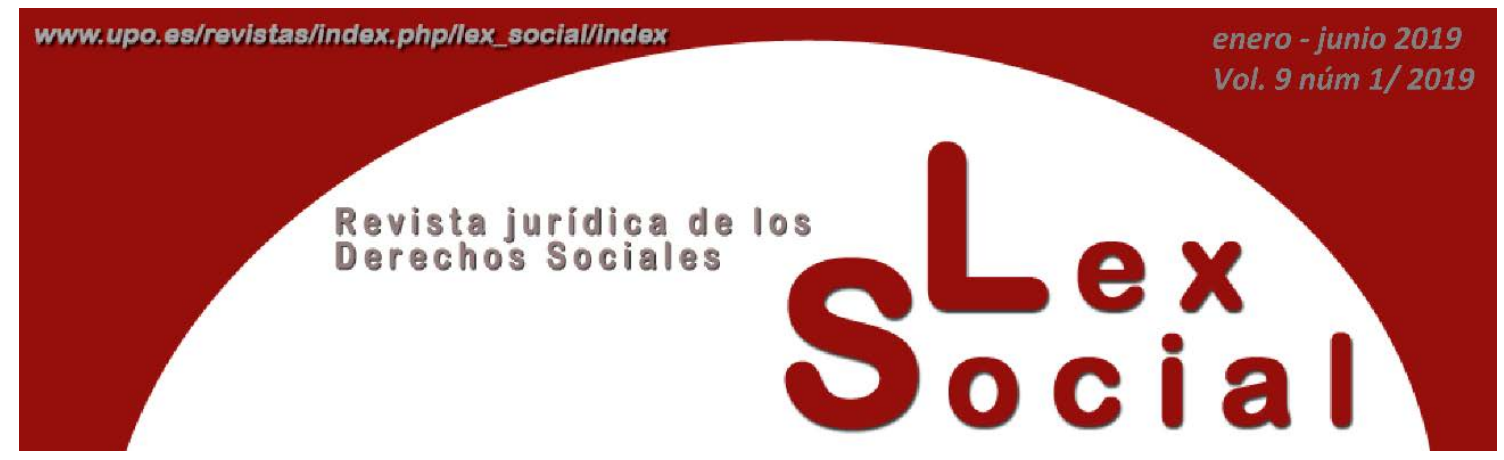

\title{
LOS DERECHOS SOCIALES EN LAS FUENTES DEL DERECHO MARROQUÍ Y EL PAPEL DEL JUEZ EN SU PROTECCIÓN
}

\author{
SOCIAL RIGHTS IN MOROCCAN SOURCES OF LAW AND THE \\ ROLE OF THE JUDGE IN THEIR PROTECTION
}

\author{
ABDELHAMID ADNANE \\ Profesor de Derecho constitucional \\ Centro Euro-Árabe de estudios Jurídicos Avanzados ${ }^{1}$
}

Artículo recibido el 15 de marzo de 2019

Artículo aceptado el 20 de marzo de 2019

\section{RESUMEN}

La Constitución marroquí, de modo directo o remitiendo al Derecho Internacional de los Derechos Humanos, recoge una serie de derechos de naturaleza prestacional imprescindibles para el desarrollo y el progreso personal y social. A pesar de no configurarse como derechos subjetivos en la norma fundamental marroquí, el juez del contencioso administrativo no dudó en recurrir, en más de una ocasión, a las fuentes internacionales para brindarles la merecida protección.

Palabras Clave: Derechos sociales, Tratados internacionales, garantía judicial

\section{Abstract}

\footnotetext{
${ }^{1}$ El profesor Terol Becerra, fundador del Centro Euro-Árabe de Estudios Jurídicos Avanzados, ha sido un defensor a ultranza de los derechos sociales y de la necesaria aplicación de los estándares internacionales en la materia. Su compromiso responsable con esta categoría de derechos ha creado escuela en la doctrina marroquí que estará siempre en deuda con él.
} 
The Moroccan Constitution, directly or by reference to international human rights law, contains a number of social rights necessary for personal and social development and progress. Although it did not take the form of subjective rights in the Moroccan fundamental norm, the administrative court did not hesitate to resort, on more than one occasion, to international sources in order to provide it with the appropriate protection.

KEY WORDS: Social rights, International deals, judicial guarantee.

SUMARIO

Ideas introductorias.

1. Coordenadas sociales en la Constitución marroquí.

2. Los Tratados sobre derechos humanos en la Constitución y su posición en el sistema de la Fuentes.

3. Poder judicial y protección de los derechos sociales con base en la Constitución y en la norma internacional.

A. El derecho a la enseñanza superior.

B. El derecho a la salud.

C. El derecho la cultura.

Consideraciones finales.

\section{Ideas introductorias}

Es sabido que a partir de la segunda mitad del siglo dieciocho, el individuo gobernado pasa a ocupar, de manera central, la atención de los autores políticos. Ello representó un punto de inflexión histórico definido por Norberto Bobbio como "la revolución copernicana de la modernidad”2.

A partir de entonces resurge también la idea aristotélica del "gobierno de las leyes” que será enriquecida por Rousseau en su nueva concepción de la soberanía como elemento definitorio del status del pueblo. Este status será recogido y garantizado en la norma fundamental de la nueva forma de organización política. Pues a partir de finales

\footnotetext{
${ }^{2}$ Cfr. Bobbio, N., El tiempo de los derechos, Madrid, Sistema, 1991, pág. 105.
} 
de esta fecha, el reconocimiento de los derechos fundamentales y las libertades públicas se torna consustancial al sistema constitucional ${ }^{3}$.

En línea con ello, con las primeras positivaciones iniciadas a finales del siglo XVIII en ambos lados del atlántico se inicia la moderna configuración de las libertades caracterizada principalmente por una fundamentación iusnaturalista racionalista de los derechos; el triunfo de la universalización e individualización de los derechos, desvinculándose del carácter iusprivatista de los antiguos textos; un reconocimiento de los derechos ligados íntimamente al movimiento constitucionalista del Estado Liberal y una clara impregnación de los derechos, del carácter liberal de la época, ya que son libertades «negativas» o «civiles » que pretenden conseguir la libre y privada acción del individuo, sin injerencias ni intervencionismos públicos ${ }^{4}$.

El siglo XIX aporta una "progresiva relativización del contenido iusnaturalista de los derechos" ${ }^{5}$, que sirve finalmente a la burguesía para afianzar y conservar el poder político, imponiendo una lectura «dirigista » de las libertades. Y ello mientras el modelo angloamericano de derechos continúa ligado a su tradición historicista y fuertemente garantista de los mismos, donde los jueces son depositarios de la garantía de las libertades. En Estados Unidos la Constitución se impone para garantizar los derechos mientras en la Europa continental es la ley estatal, la propia autoridad gobernante quien los defiende ${ }^{6}$.

En definitiva, se llega en Europa a una débil eficacia de los catálogos de derechos de las Constituciones y un retroceso de la idea de libertad como límite frente al poder, al reconducirse los derechos a la voluntad del legislador. Esta fue la situación en la que también se encontraba, aunque con sus propias particularidades, el constitucionalismo marroquí anterior al 2011.

Llegados aquí, no huelga recordar que si el Estado liberal de comienzos del siglo diecinueve era claramente abstencionista y sólo intervenía para la defensa de la seguridad y del orden público, de la libertad y de la propiedad, su nueva configuración como Estado social y de ahí, ineludiblemente, intervencionista, obliga a reforzar los medios clásicos de control de la Administración pública estableciendo nuevos modos de dar respuesta a los posibles agravios a los que puede dar lugar dicha expansión administrativa. Este

\footnotetext{
${ }^{3}$ Grimm, D., Constitucionalismo y derechos fundamentales, Trotta, Madrid, 2006; Ferrajoli, L., Derechos y garantías. La ley del más débil, Trotta, Madrid, 2002 y Los fundamentos de los derechos fundamentales, Trotta, Madrid 2003; Díez-Picazo, L.M., Sistema de Derechos Fundamentales, Civitas, Madrid, 2003; Pérez Luño, A., Derechos Humanos, Estado de Derecho y Constitución, Tecnos, Madrid, 2005.

${ }^{4}$ Cfr. Álvarez Conde, E., "Los derechos en el constitucionalismo: tipología y tutela «multinivel»”. Teoría y Realidad Constitucional, núm. 20, 2007, Páginas 233-234.

${ }^{5}$ Ibíd. pág. 234

${ }^{6}$ Fioravanti, M., Los derechos fundamentales. Apuntes de historia de las Constituciones, Trotta, Madrid, 1998, pp. 112 ss. Citado por Álvarez Conde, E,. “Los derechos en el constitucionalismo...”, Op. Cit... pág. 234.
} 
postulado del Estado social, al que se atribuye una fuerza integradora, está orientado a lograr una compensación de los intereses y el fomento del bien común ${ }^{7}$.

Dicho postulado, anunciado en el artículo primero de la Constitución marroquí, constituye un claro mandato a los poderes públicos para la realización efectiva del principio de igualdad material, que por otro lado tiene claro apoyo en el artículo 6.2 de la norma fundamental. Ambos artículos del texto constitucional indican las vías a seguir para que los ciudadanos disfruten del bienestar material, alcanzable, entre otros, a través de los derechos sociales contenidos en el ordenamiento jurídico.

Prescindiendo ahora de los antecedentes históricos de la Constitución marroquí del 2011, apreciamos que se inicia una nueva fase que, en la tónica de los modernos Estados Constitucionales, introduce un completo catálogo de derechos de signo liberal, democrático y económico-social. Nuestro objeto de estudio se limita a los derechos sociales que pasaremos a repasar en la norma fundamental marroquí, que remite a su vez al Derecho Internacional para su interpretación y para su protección. Especial hincapié en este recorrido se hará sobre el papel del juez del contencioso administrativo en su protección al invocar en reiteradas ocasiones en sus sentencias la norma internacional.

\section{Coordenadas sociales en la Constitución marroquí}

Si el fundamento de los derechos de primera generación era la «libertad», el de la segunda era la «igualdad». El individualismo y el carácter abstracto del sistema de derechos evidenciarán al llegar el siglo XX las enormes deficiencias que contenía: los documentos constitucionales constituían simples proclamaciones formales que en muchos aspectos se alejaban de una realidad social presidida por la desigualdad y complicada por los cambios tecnológicos, industriales, económicos y sociales. En definitiva, se trataba de reivindicar al Estado la garantía de existencia de condiciones básicas de vida de las personas que éstas no son capaces de lograr por sí mismas la llamada "procura existencial»: una igualdad real, que además se hiciera valer incluso frente al legislador.

La Constitución marroquí ${ }^{8}$ recoge en su articulado una serie de derechos de naturaleza prestacional que se presentan como concreciones de varias disposiciones: del artículo 1 que define Marruecos como una monarquía constitucional, democrática, parlamentaria y social; del artículo 6.2 que dirige mandatos a los poderes públicos para crear las condiciones susceptibles de generalizar la efectividad de la libertad y de la igualdad de los ciudadanos así como a favorecer su participación en la vida política,

\footnotetext{
${ }^{7}$ Benda, E. "El Estado Social de Derecho", en Benda, Maihofer, Vogel Hesse, Heyde, en Manual de Derecho Constitucional, Presentación de Conrad Hesse; edición, prolegomenada y traducción de López Pina, A, Madrid: Marcial Pons Ediciones Jurídicas y Sociales; Instituto Vasco de Administración Pública, 1996; pp. 487 y ss. Citado por Jutta Limbach “Papel y poder del Tribunal Constitucional.” Teoría y Realidad Constitucional, n. ${ }^{\circ}$ 4, 1999, pág. 110.

${ }^{8}$ Boletín oficial $n^{\circ} 5964$ bis du 28 chaabane 1432 (30/07/2011).
} 
económica, cultural y social, y del artículo $35^{9}$ que evoca el concepto de justicia social llamado a modular el ejercicio de ciertos derechos de naturaleza económica.

Dicho esto, cabe precisar que en el texto constitucional marroquí sólo encontramos dos derechos configurados como verdaderos derechos subjetivos, eso es cuya infracción puede ser directamente denunciable en sede judicial. Se trata del derecho a la educación reconocido a los niños, recogido en el artículo $32^{10}$, y del derecho a la gratuidad de la justicia previsto en el artículo $121^{11}$ de la norma fundamental.

Por otro lado, el artículo 31 de la CM configura una serie de derechos sociales pero que subordina su pleno disfrute a los medios disponibles. En esta categoría encontramos el derecho a los cuidados sanitarios, a la protección social, a una educación moderna, accesible y de calidad, a la formación profesional y a la educación física y artística, a una vivienda decente, al trabajo y al apoyo de los poderes públicos en materia de búsqueda de empleo y de autoempleo, al acceso al agua y a un medio ambiente salubre.

La tercera categoría dispuesta en los artículo $26^{12}$, $33^{13}$ y $34^{14}$ dirige mandatos al legislador para apoyar el desarrollo de la actividad cultural y artística; apoyar la investigación científica y técnica; promover el deporte, generalizar la participación de los jóvenes en el desarrollo social, económico, cultural y político del país; ayudar a los jóvenes para pasar a la vida activa; prestar ayuda a aquellas personas que tienen dificultades de adaptación escolar, social y profesional; facilitar el acceso de los jóvenes

\footnotetext{
9 “...El Estado vela para garantizar la igualdad de oportunidades para todos y una protección específica para todas las categorías sociales desfavorecidas.”

10 "La familia, fundada sobre el vínculo legal del matrimonio es la célula básica de la sociedad. El Estado actúa para garantizar, por medio de la ley, la protección de la familia sobre los planos jurídico, social y económico, de modo que pueda garantizar su unidad, estabilidad y preservación.

Asegura una igual protección jurídica y una igual consideración social y moral a todos los niños, independientemente de su situación familiar.

La educación básica es un derecho del niño y una obligación de la familia y del Estado.”

11 "En los casos previstos por la ley la justicia es gratuita para aquellos que no dispongan de recursos suficientes para entablar un proceso.”

12 "Los poderes públicos aportan, por los medios apropiados, su apoyo al desarrollo de la creación cultural y artística, y de la investigación científica y técnica, así como a la promoción del deporte. Favorecen el desarrollo y la organización de estos sectores de manera independiente y sobre bases democráticas y profesionales precisas.”

13 "Incumbe a los poderes públicos tomar todas las medidas apropiadas para:

- extender y generalizar la participación de la juventud en el desarrollo social, económico, cultural y político del país;

- ayudar a los jóvenes a insertarse e la vida activa y asociativa y a prestar asistencia a aquellos con dificultad de adaptación escolar, social o profesional;

- facilitar el acceso de los jóvenes a la cultura, la ciencia, la tecnología, el arte, el deporte y el ocio, creando las condiciones propicias para el pleno despliegue de su potencial creativo e innovador en todos estos aspectos.

Se crea a este efecto un Consejo consultativo de la juventud y de la acción asociativa.”

14 “Los poderes públicos elaboran y ponen en práctica políticas destinadas a las personas y a las categorías con necesidades específicas. A este efecto, velan, en particular, por:

- tratar y prevenir la vulnerabilidad de ciertas categorías de mujeres y de madres, de niños y de ancianos;

- rehabilitar e integrar en la vida social y civil a los minusválidos físicos sensomotores y mentales, y facilitar su disfrute de los derechos y libertades reconocidos a todos.”
} 
a la cultura, a la ciencia, a la tecnología, al arte, al deporte y al ocio; tratar y prevenir la vulnerabilidad de ciertas categorías de mujeres y madres, de niños y de personas de la tercera edad y rehabilitar e integrar en la vida social y civil a los minusválidos físicos, sensoriales y mentales.

Se trata de una lista bastante extensa de posibilidades de acción previstas por el constituyente en beneficio del bienestar material de los ciudadanos. Dicho esto, y sabiendo que el derecho vale lo que tiene de garantía, veamos cuales son las posibles garantías de las tres categorías expuestas relativas a los derechos de naturaleza prestacional.

Tocante a la primera categoría que configura derechos subjetivos, el constituyente no los distingue en cuanto a su protección de los demás derechos fundamentales, encargándose el poder judicial de ello y, cabiendo la impugnación de cualquier disposición legislativa que los desconozca ante la Corte Constitucional.

Respecto a la segunda categoría, su disfrute depende de los medios disponibles, por lo que la amplitud de las facultades y prerrogativas reconocidas a su titula depende de los recursos económicos disponibles. Sabemos a este respecto que la afectación de los recursos y la determinación de su cuantía dependen de un juicio de oportunidad realizado por el poder político. No obstante, incluso en tiempo de crisis o de contracción económica el legislador debe mantener un mínimo de facultades sin la cuales el derecho se convertiría en un mero nominalismo hueco de contenido. Creemos que, con relación a esta categoría, cabría un control de constitucionalidad de la ley cuyo objetivo sería comprobar el mantenimiento de ese mínimo que, por otra parte, es necesario para salvaguardar la dignidad de los individuos integrantes de la comunidad.

Por último, y con relación a los mandatos dirigidos al legislador afirmamos que, por razón de esta configuración, quedan plenamente a disposición del legislador y no está previsto ningún procedimiento que permita incoar el control de la inacción legislativa. Pero ¿quiere ello decir que el legislador al abordarlos puede hacer lo que estime oportuno? Una respuesta afirmativa supondría la posibilidad de un vaciamiento total del contenido de los derechos sociales afectados por esta intervención legislativa. Pues, este límite no previsto expresamente en la Constitución puede encontrarse en la jurisprudencia elaborada por los órganos de control creados por los Tratados ratificados por el Estado marroquí. Jurisprudencia que permitiría, sin sombra de duda, integrar el contenido inalcanzable por la acción legislativa en su labor configuradora de los derechos fundamentales.

\section{Los Tratados sobre derechos humanos en la Constitución marroquí y su posición en el sistema de la Fuentes}

Es de sobra conocido que hace tiempo ya que los derechos fundamentales de las personas han dejado de pertenecer al ámbito interno de los Estados y de ser, con ello, algo 
estrictamente constitucional y, por tanto, doméstico. La Declaración Universal de los Derechos Humanos inició un camino por el que posteriormente han transitado otros instrumentos internacionales que han declarado y garantizado un catálogo de derechos y libertades que vinculan incluso a los Estados, con la pretensión de que fueran respetados en sus respectivos ámbitos territoriales.

Todas las Constituciones marroquíes anteriores a la del año 2011 fueron marcadas por la imprecisión en cuanto a la posición de los Tratados en la jerarquía normativa, a pesar de que sus preámbulos afirmaran que el Estado suscribe los principios, derechos y obligaciones que emanan de los documentos constitutivos de los organismos internacionales de los que forma parte, y precisan su compromiso con los derechos humanos tal como son universalmente reconocidos. No obstante, ninguna disposición normativa aborda la cuestión de su rango jerárquico ${ }^{15}$. Este silencio del constituyente marroquí pudo interpretarse como una voluntad manifiesta de no acordar a todos los Tratados una fuerza superior y ni siquiera igual a la de la ley ${ }^{16}$.

Es sabido que el tratamiento jurídico de los Tratados internacionales y de su posición en el Derecho interno no es uniforme en todos los Estados. Algunos países acuerdan por imperativo constitucional un rango de privilegio a los Tratados en la jerarquía normativa, eso es una posición superior a la ocupada por la Ley, mientras que otros no abordan claramente esta cuestión y dejan en manos de la jurisdicción la determinación de sus efectos normativos, lo que da lugar a una diversidad de puntos de vista interpretativos ${ }^{17}$.

No cabe duda de que los Tratados debidamente suscritos deben forzosamente gozar de pleno respeto a nivel nacional, pues así se da aplicación al famoso principio de Derecho Internacional, Pacta sunt servanda, recordado en la Convención de Viena sobre el Derecho de los Tratados. En virtud de ello, no puede alegarse la cualidad soberana del Estado para sustraerse a la aplicación de las disposiciones de un Tratados al cual ha adherido libremente, a sabiendas que todo Estado dispone de un ordenamiento jurídico que permite la aplicación automática de las normas convencionales o bien su aplicación indirecta mediante la intervención del legislador.

Tanto el preámbulo ${ }^{18}$ de la Constitución marroquí de 2011, de carácter normativo en virtud de la norma fundamental, como varias disposiciones de la misma afirman la

\footnotetext{
15 A partir de esta constatación el juez constitucional en 1963 llega a declarar su incompetencia para controlar la conformidad de los Tratados internacionales con la Constitución alegando que ésta no le atribuye dicha competencia. Sentencia $n^{\circ} 1$ del 31 de diciembre 1963, B.O. $n^{\circ} 2672$ del 10 de enero 1964, pág. 52.

${ }^{16}$ Benabdallah, M.A. “Les Traités en Droits Marocain”. REMALD, n 94, septembre-octobre 2010, pág. 160.

${ }^{17}$ Benabdallah, M.A. “Les Traités en Droits Marocain”. Op. cit, pág. 159.

18 “Teniendo en cuenta el imperativo de reforzar el papel que le corresponde en la escena internacional, el Reino de Marruecos, miembro activo en el marco de las organizaciones internacionales, se compromete a suscribir los principios, derechos y obligaciones enunciados en sus respectivas cartas y convenciones; reafirma su compromiso con los derechos humanos tal como son universalmente reconocidos, así que su
} 
supremacía de los Tratados internacionales debidamente ratificados sobre el Derecho interno infra-constitucional y el compromiso del Estado marroquí con los derechos humanos tal como están reconocidos y garantizados a nivel internacional.

La supremacía de la Constitución sobre los Tratados es una cuestión pacífica en la doctrina constitucionalista, y zanjada con claridad por el artículo 55 de la Constitución marroquí que abre la posibilidad a que los Tratados internacionales puedan ser deferidos ante la Corte Constitucional para asegurarse de su constitucionalidad antes de su ratificación ${ }^{19}$.

En cuanto a la eficacia directa de los Tratados internacionales, a nuestro juicio, no ha de suscitar polémica alguna ya que su fuerza normativa emana de la Constitución misma $^{20}$. Entiéndase por ello los Tratados suscritos y debidamente ratificados. Ahora bien, la cuestión que ha dado lugar a ciertos debates doctrinales respecto de la fuerza normativa de los Tratados y su aplicación directa trae causa de la reforma constitucional del 2011, que en cuya virtud se ha procedido a la ampliación del ámbito material de la Ley, eso es del ámbito competencial del Parlamento. De hecho, el nuevo texto amplía notablemente las competencias del órgano legislativo disponiendo que la regulación de los derechos y libertades ha de ser por Ley (en la Constitución anterior el ámbito de la Ley era bastante reducido, lo que daba lugar a que el Gobierno podía regular derechos y libertades). Esta innovación justifica el hecho de que la ratificación de los Tratados sobre derechos humanos (entre otros) sea competencia del legislador y no del poder ejecutivo como era el caso según la Constitución anterior de 1996.

Esta intervención de dos órganos en la adopción y ratificación de los Tratados puede dar a entender que Marruecos sigue el modelo dualista. Sin embargo, estimamos que el criterio a usar para saber si se trata de un modelo monista o dualista no es el número de órganos intervinientes en este proceso sino la naturaleza de la ratificación parlamentaria. Es decir, si el órgano a quien corresponde la ratificación (en este caso el Parlamento marroquí) se limita a consentir la integración en sus propios términos de la regulación contenida en el Tratado en el orden nacional o bien puede operar una transposición del referido contenido en una ley, lo que le habilita a una adaptación de los enunciados del Tratado al contexto nacional. Dicho esto, y atendiéndose al tenor del

\footnotetext{
voluntad de seguir obrando para preservar la paz y la seguridad en el mundo"... "Marruecos se compromete a proteger y promover los dispositivos de los derechos humanos y del Derecho Internacional Humanitario y a contribuir a su desarrollo a partir de indivisibilidad y universalidad”. (Traducción mía).

19 “... Si el Tribunal Constitucional, requerido por el rey o por el Jefe del Gobierno o el presidente de la Cámara de representantes o el presidente de la Cámara de consejeros, o la sexta parte de los miembros de la primera Cámara o la cuarta parte de los miembros de la segunda Cámara, declaran que un compromiso internacional contiene una disposición contraria a la Constitución, su ratificación sólo puede realizarse tras la revisión de la Constitución."

${ }^{20}$ Recuérdese, además, que la Convención de Viena del 23 de mayo 1969 sobre el Derecho de los Tratados, ratificada por el Estado marroquí por Dahir de 8 de agosto 1973, B.O. no 3239 de 27 de noviembre 1974, pág. 1626, precisa en su artículo 26 que "Todo tratado en vigor obliga a las partes y debe ser cumplido por ellas de buena fe”. Así mismo, añade en el artículo 27 que "Una parte no podrá invocar las disposiciones de su derecho interno como justificación del incumplimiento de un tratado”.
} 
artículo 55 de la Constitución marroquí, se colige que la competencia del Parlamento se limita a "aprobar" el texto del Tratado y no alcanza la posibilidad de transposición de su contenido a una ley ${ }^{21}$.

De lo expuesto se deduce que el modelo marroquí sigue el sistema monista, por lo que la ratificación de un Tratado por el órgano competente le dota de fuerza normativa, y le permite surtir efectos en el orden nacional con la posibilidad de que, llegado el caso, sus disposiciones puedan ser invocadas ante el juez competente.

Por último, tocante a la posición de los Tratados en el sistema de Fuentes, la Constitución es clara en este sentido y decreta la supremacía de los Tratados debidamente ratificados sobre el orden jurídico nacional (evidentemente el orden infra-constitucional). Puede pensarse en la posible colisión entre una norma de rango legal y las disposiciones de un Tratado. Creemos que en caso de no recurrirse a la técnica de "reserva” admitida en el Derecho Internacional, la aprobación por Ley del contenido del Tratado ha de considerarse como derogatoria de la ley nacional (o de alguna de sus disposiciones) anterior por mera aplicación del criterio temporal (la norma posterior deroga la norma anterior). No se crea por lo tanto un escalón intermedio entre la Constitución y la Ley pues falta una previsión constitucional estableciente del control de convencionalidad de la Ley-, sino que se ha de operar (es nuestra opinión) a través del criterio temporal.

Hecha esta afirmación, cabe dejar claro que el criterio temporal invocado líneas arriba no puede usarse para derogar el contenido del Tratado por una reforma legal posterior, pues la ley de aprobación de los Tratados es una "falsa ley” en el sentido de que es el producto de la participación de dos órganos: el Gobierno en su negociación y el Parlamento en su adopción. Su reforma o derogación no puede hacerse por la única voluntad del Parlamento sino que, en aplicación del principio de paralelismo de las formas, requeriría de la concurrencia de los dos órganos (Gobierno y Parlamento).

Como colofón a este breve recorrido, concluimos que una vez aprobado por una Ley el contenido de un Tratado pasa a integrar el ordenamiento jurídico marroquí al que han de someterse todos los poderes del Estado.

Las cláusulas de apertura contenida en la carta magna marroquí se inscriben en la línea de imponer nuevos límites, a través del Derecho Internacional, a la soberanía del Estado en sus relaciones con los ciudadanos. Limitación que afecta directamente al poder jurídico, no político, del Estado que es el Poder Judicial al imponerle “decir derecho” a la luz del contenido de los Tratados que versan sobre Derechos Humanos. Lo que viene a decir que el contenido de éstos integrado por la interpretación que de los mismos hacen los órganos encargados de su protección se erige en canon para una completa intelección

\footnotetext{
21 "No obstante, los tratados de paz o de unión, o aquellos relativos a la delimitación de las fronteras, los tratados de comercio y aquellos que comprometan las finanzas del Estado cuya aplicación precise de medidas legislativas, así como los tratados relativos a los derechos y libertades individuales o colectivas de las ciudadanas y de los ciudadanos, no pueden ser ratificados sino después de haber sido previamente aprobados por la ley”.
} 
judicial de los derechos fundamentales contenidos en el texto constitucional. Varios Tratados de contenido social han sido aprobados por ley, y ratificados por parte de las autoridades competentes en Marruecos. De todo cuando antecede, se infiere, pues, con absoluta naturalidad su invocabilidad en sede judicial y la posibilidad de que el juez nacional dicte sentencia con base en sus disposiciones. Así se ha entendido por parte de jueces del contencioso administrativo en Marruecos.

\section{Poder judicial y protección de los derechos sociales con base en la Constitución y en la norma internacional}

No resulta ocioso recordar que el poder judicial es el garante natural de los derechos. De lo que deriva que cuando el poder político del Estado, al asumir responsabilidades internacionales en virtud de Tratados o Convenios válidamente ratificado, y se compromete ante la comunidad internacional reconociendo nuevas obligaciones con respecto a sus ciudadanos, el poder jurídico resulta compelido a razonar desde el ordenamiento jurídico, ampliado continuamente por los Tratados y Convenios internacionales. Dicho de otro modo, la propuesta normativa ofrecida ora por el recurso a la norma internacional ora por vía de la interpretación que hace el poder jurídico del Estado, permite, aunque "iura novit curia", integrar el contenido de las disposiciones constitucionales aprovechando su "contextura receptiva”22, y ampliando así el ámbito normativo constitucional.

La nueva Constitución marroquí, a través de un número apreciable de disposiciones, pone los cimientos imprescindibles para la construcción de un verdadero Estado de Derecho. Traza el marco en cuyo seno ha de desplegarse la actividad política de gobierno y dispone una serie de órganos e instituciones jurídicas limitadoras de la referida actividad política en el sentido de someterla a los dictados de la norma fundamental. Ésta, en aras de asegurar su carácter normativo, además de la ceración y la reconfiguración de las instituciones que traen su origen y régimen jurídico de la anterior Constitución, ha establecido un verdadero Poder Judicial separado funcional y orgánicamente de los poderes políticos estatales: Parlamento y Gobierno.

En virtud del nuevo texto, la justicia deja de ser considerada como una "autoridad" para convertirse en un poder al pie de igualdad que el legislativo y el ejecutivo. Sin entrar en las diferencias históricas y doctrinales entre las nociones de Poder y Autoridad, cabe adelantar que el cambio de denominación pretende tanto blindar la judicatura frente a injerencias externas como fortalecer el estatus ciudadanos en cualquier proceso, especialmente el penal, blindando de este modo el prestigio de los jueces (auctoritas) y equilibrando sus facultades (potestas) con los poderes políticos mencionados.

\footnotetext{
22 Expresión Miguel Ángel APARICIO PÉREZ: “La cláusula interpretativa del artículo 10.2 de la Constitución Española, como cláusula de integración y apertura constitucional a los derechos fundamentales”, In Jueces para la democracia, ISSN 1133-0627, № 6, 1989, pag.14.
} 
Con relación a la función del juez, la Constitución marroquí hace del poder judicial el garante natural de los derechos fundamentales en virtud del artículo $117^{23}$, tarea que asumirá el juez en general, y el juez del contencioso administrativo en especial.

De hecho, los Tribunales administrativos en Marruecos han tenido la ocasión de pronunciarse sobre asuntos relacionados con los derechos sociales inscritos en la Constitución. Sin pretender elaborar una lista exhaustiva de tales decisiones, ni presentar un balance estadístico completo sobre este particular, nuestro propósito se limita a poner en evidencia las decisiones más destacadas en cuanto ponen en relación el ordenamiento jurídico nacional con el Derecho internacional.

Destaca del análisis de las mencionadas decisiones, que ciertos jueces administrativos mostraron una dosis de activismo a favor de los derechos de carácter social. Tres ejemplos lo confirman: decisiones relativas al derecho de acceso a la enseñanza superior (A); otras se refieren al derecho a la salud (B) y las últimas relacionadas con el derecho a la cultura $(\mathrm{C})$.

\section{A. El derecho a la enseñanza superior}

Después de la entrada en vigor de la reforma pedagógica en el ámbito universitario durante el curso 1997-1998, el juez administrativo fue llamado a pronunciarse sobre el derecho a la educación, tras varios recursos interpuestos por estudiantes a los cuales se les ha denegado el derecho a matricularse en los estudios de tercer ciclo ya que, a juicio de la Administración, carecían de la calificación necesaria para poder acceder a dichos estudios $^{24}$. Así, en numerosos casos, el juez administrativo se mostró protector del derecho al acceso incondicional a la enseñanza superior ${ }^{25}$. Los diferentes casos han tenido semejante respuesta por parte del poder judicial, confirmando que no le correspondía a la Administración limitar el derecho de matrícula, y las justificaciones de los jueces giraban en torno al rango constitucional del derecho a la educación ${ }^{26}$ y a su mención en las normas convencionales relativas a los derechos humanos ${ }^{27}$.

Esta actitud parece ir más lejos de las interpretaciones más protectoras del derecho a la enseñanza superior, a la vista particularmente de normas convencionales en la materia. Con este fin, una mera consulta de los textos convencionales permite constatar

\footnotetext{
23 “Le juge est en charge de la protection des droits et libertés et de la sécurité judiciaire des personnes et des groupes, ainsi que de l'application de la loi.”

24 Rbii, H., “Droits de l'Homme au Maroc: bilan succinct d'une décennie (1999-2009)”, in Revue Marocaine de l’Administration Locale et du Développement, numéro double 94-95, septembre-décembre 2010, pág. 99.

25 Ibid., pág. 97.

${ }^{26}$ Benabdallah, M.A, "L'inscription au diplôme d'études supérieures approfondies, Note sous T.A., Rabat, 30 juin 1999, Daouda et autres”, in Revue Marocaine de l'Administration Locale et du Développement $n^{\circ}$ 30, 2000, $\quad$ pp. $81 \quad$ y $\quad$ ss. $\quad$ Disponible $\quad$ en http://aminebenabdallah.hautetfort.com/list/droit_administratif/inscription_desa.pdf

${ }^{27}$ RBII (H.), “Droits de l’Homme au Maroc: bilan succinct d’une décennie (1999-2009)”, op.cit., pág. 97.
} 
que el derecho a la educación tiene, por lo menos, tres aspectos: la enseñanza primaria debe ser obligatoria y accesible gratuitamente a todos; la enseñanza secundaria, incluido la enseñanza técnica y profesional, debe ser generalizada y accesible a todos, especialmente por la instauración progresiva de la gratuidad; mientras que el acceso a los estudios superiores debe ser configurado en igualdad plena a ellos todos con arreglo a su mérito y capacidades ${ }^{28}$.

Esta distinción tridimensional de los niveles del derecho a la educación ha sido confirmada por otro lado por el Comité de los derechos económicos, sociales y culturales que subrayó que la obligación de asegurar el ejercicio de este derecho no era la misma para todos los niveles o todos los tipos de enseñanzas ${ }^{29}$, y precisa que "la enseñanza superior no "debe ser generalizada", sino sólo disponible "sobre la base de la capacidad que habrá de valorarse con respecto a los conocimientos especializados y la experiencia de cada cual”30.

Queda patente que el juez administrativo marroquí dio prueba de un activismo a favor del derecho al acceso incondicional a la enseñanza superior, aunque sus justificaciones, en ciertos casos, puedan prestar a discusión, dado que debería haberse esforzado un poco más para sostener de manera más sólida sus decisiones. Tal esfuerzo se encuentra sin embargo en otras decisiones que se refieren, esta vez, al derecho a la salud.

\section{B. El derecho a la salud}

Contrariamente al derecho a la educación que fue recogido en todas las Constituciones marroquíes desde 1962, el derecho a la salud no tuvo tal suerte y hubo que esperar hasta la aprobación de la Constitución de 2011.

Sin embargo, en numerosas ocasiones, el juez administrativo fue requerido para pronunciarse sobre este derecho. Lo esencial de su jurisprudencia se remite a la responsabilidad por falta de los servicios públicos, y en estos casos concretos al servicio de salud ${ }^{31}$.

No obstante, dos casos relativos al derecho a la salud en su dimensión de "derecho fundamental”, pudieron llegar hasta la Corte suprema, merecen una atención particular.

\footnotetext{
${ }^{28}$ Véase el artículo 26.1 de la DUDH y el artículo 13.2 del PIDESC.

${ }^{29}$ Comité des DESC, «Observation générale $\mathrm{N}^{\circ}$ 13: Le droit à l'éducation», in HRI/GEN/1/Rev.9 (Vol. I), Récapitulation des observations générales ou recommandations générales adoptées par les organes créés en vertu d'instruments internationaux relatifs aux droits de l’homme, pág. 86, § 48.

${ }^{30}$ Ibid., pág. 81, § 19.

${ }^{31}$ Cfr. Rbii, H., "Droits de l'Homme au Maroc: bilan succinct d'une décennie (1999-2009)”, op.cit., pp. 99-100; Ben Sedrine, L., "La responsabilité du médecin au Maroc”, in REMALD, numéro double n 62-63, mai-août 2005, pp. 53-70; Ben Sedrine, L., «La responsabilité administrative des hôpitaux publics au Maroc», in Revue Marocaine de l'Administration Locale et du Développement, numéro double 84-85, janvier-avril 2009, pp. 595-199.
} 
El primero se refiere a una paciente que falleció tras el empeoramiento de su estado de salud durante una hospitalización que contaba con numerosos servicios en dos hospitales, y cuyas decisiones tomadas con torpeza fueron la causa directa de la defunción.

Aunque este caso puede incardinarse en un supuesto de responsabilidad del Estado por un funcionamiento defectuoso de los servicios públicos de la salud, llama poderosamente la atención en tanto en cuanto el juez invocó, en su sentencia, el derecho humano a la salud y a la vida refiriéndose a los convenios internacionales y regionales que lo garantizaban, y citando expresamente un pasaje del preámbulo de la Constitución de la OMS que dispone que "El goce del grado máximo de salud que se pueda lograr es uno de los derechos fundamentales de todo ser humano sin distinción de raza, religión, ideología política o condición económica o social” ${ }^{32}$.

Interesa precisar que la referencia a las normas convencionales, en este caso, resultó lacónica, dado que el juez habría podido dar más peso a su argumentación y su justificación si hubiera invocado los instrumentos internacionales, garantizando el derecho a la salud y vinculando al Estado, tal como es el caso del Pacto Internacional relativo a los derechos económicos, sociales y culturales ratificado por Marruecos. Dicho esto, no se deprecie este esfuerzo jurisdiccional en una tradición que raramente acude a las normas convencionales relativas a los derechos humanos, y menos todavía a las que se remiten a los derechos sociales.

El Tribunal estimó que la decisión del servicio de hemodiálisis de parar la depuración artificial de la sangre del paciente, por falta de medios financieros, que causó su defunción según el resultado del peritaje ordenado por el Tribunal, es contraria al derecho a la salud y a la vida. Añade que por ello resulta constitutiva de una vulneración del principio de igualdad de acceso al servicio público de la salud, que es sinónimo de una discriminación fundada sobre la condición económica y social. El Estado marroquí resultó, así, condenado al pago, en reparación del daño causado, de la cantidad de 320.000 Dirhams.

Este caso, tras la interposición de los recursos pertinentes, llegó ante la Corte suprema que no dudó en confirmar ${ }^{33}$ la sentencia del Tribunal inferior, pero, en contra de lo esperado, no hizo mención alguna de los Tratados internacionales como fuente de Derecho invocable en sede judicial

En el segundo caso, el Tribunal Administrativo de la ciudad de Agadir, tuvo la ocasión para confirmar su jurisprudencia con relación al derecho a la salud. En este proceso, el demandante que sufre de una enfermedad cuyos gastos de cuidados se elevan a seiscientos mil dirhams, reclamó, con base en el derecho a la salud, que el Estado

\footnotetext{
${ }^{32}$ Véase el preámbulo de la constitución de la OMS en https://www.who.int/about/mission/es/

${ }^{33}$ Cour suprême, Chambre administrative, Arrêt $n^{\circ} 181$, 21 février 2007, État marocain et autres c./ Héritiers Daouya Bent Mohammed (En árabe), in REMALD, n 89, novembre-décembre 2009, pp. 169171.
} 
marroquí le facilitase el tratamiento y los cuidados necesarios, en instituciones hospitalarias nacionales o en el extranjero. El Tribunal acudió una vez más, y de una manera más amplia, a las normas convencionales de protección del derecho a la salud, y llegó a la conclusión de que queda probada la responsabilidad del Estado por falta de prestación de los cuidados adecuados a la recurrente, y le requirió para hacerse cargo de los gastos y cuidados necesarios que exige el tratamiento del demandante ${ }^{34}$.

\section{El derecho la cultura}

En un caso sustanciado ante el juez del contencioso administrativo de Rabat ${ }^{35}$, la Administración ha definido el concepto de cultura con base en el Decreto relativo a las atribuciones y organización del Ministerio de cultura que limita el sentido de la cultura al patrimonio arquitectural, monumental, etnográfico y museográfico, al patrimonio oral, la promoción del libro, las artes teatrales, la música y la danza, las artes plásticas y a las danzas populares. Esta base interpretativa le sirvió a la Administración para demostrar que la asociación requirente debe contar con una autorización previa para organizar una formación sobre los derechos humanos, de conformidad con el artículo 3 de la ley relativa a las concentraciones públicas, pues, a su juicio, no se trata de una actividad cultural.

El Tribunal estima que la interpretación de la Administración resulta de un “abuso de lenguaje” que delimita la noción de cultura en el marco de los servicios culturales clásicos garantizados por el poder central. A su juicio la interpretación aplicable al caso es la realizada por la UNESCO que define la cultura como "el conjunto de los rasgos distintivos, espirituales y materiales, intelectuales y afectivos que caracterizan a una sociedad o un grupo social. Ella engloba, además de las artes y las letras, los modos de vida, los derechos fundamentales del ser humano, los sistemas de valores, las tradiciones y las creencias y que la cultura da al hombre la capacidad de reflexionar sobre sí mismo. Es ella la que hace de nosotros seres específicamente humanos, racionales, críticos y éticamente comprometidos. A través de ella discernimos los valores y efectuamos opciones. A través de ella el hombre se expresa, toma conciencia de sí mismo, se reconoce como un proyecto inacabado, pone en cuestión sus propias realizaciones, busca incansablemente nuevas significaciones, y crea obras que lo trascienden”.

Precisa el Tribunal que no cabe distinguir esta definición de su significado jurídico, pues debe ir de la mano de la definición universalmente reconocida y concluye, de este modo, que la asociación no necesita una autorización previa ya que se trata de una actividad de índole cultural ${ }^{36}$.

\footnotetext{
34 Tribunal Administratif d’Agadir, Lamti Nezha c./ ministre de la santé, 27 avril 2007, Gazette du palais, nº 19, janvier 2008, pág. 238.

35 Se trata de una demanda presentada por la Asociación marroquí de los derechos humanos contra el ministerio de la Juventud y de Deporte, por razón de la prohibición del uso del centro "Bouhlal” en Rabat para la organización de una formación sobre los derechos humanos.

36 Tribunal administrativo de Rabat, 19/01/2015, Asociación marroquí de derechos humanos contra el ministro de la Juventud y del Deporte.
} 
En el mismo orden de ideas, otra sentencia del Juez del contencioso administrativo de Rabat ha anulado una decisión del Wali de Rabat que prohíbe la organización de una conferencia de la Asociación marroquí de los derechos humanos ${ }^{37}$.

En otro caso, el juez que considera que la cultura engloba varios aspectos, incluida la enseñanza y la educación, anula la decisión administrativa del presidente del consejo comunal que prohíbe la construcción de una escuela. La ratio dicidendi de la sentencia parte de la consideración de que las colectividades territoriales tienen como misión promover la creación cultural y artística y desarrollar la investigación científica y técnica para alcanzar una enseñanza moderna, accesible y de calidad (artículos 25, 26, 31, 32 y 33 de la Constitución). Por estas razones estima que el acto administrativo carece de sostén jurídico, pues no se inscribe ni el espíritu de la Constitución ni en la lógica de los Tratados internacionales ${ }^{38}$.

Así mismo el juez marroquí, en su labor de protección de la cultura reiterada en otro caso, prohíbe la demolición de un edificio en proceso de clasificación como patrimonio nacional ${ }^{39}$.

En un caso parecido el juez afirma que la preservación y la protección del patrimonio cultural es una responsabilidad del presidente del Consejo comunal en virtud del artículo 50 de la Carta comunal ${ }^{40}$.

\section{Consideraciones finales}

Como es harto sabido, la Constitución es una norma de mínimos que establece los cauces para la autodirección política de la sociedad, pero que requiere en muchos puntos de la acción del legislador para desarrollar sus contenidos. Éste está llamado a ser respetuoso, en lo que afecta a los derechos fundamentales en general, y a los derechos sociales en particular, de los contornos trazados por el constituyente en su labor reguladora de los mismos, so pena de incurrir en inconstitucionalidad. Le corresponde también, en el mismo grado, ser considerado con el contenido de los Tratados suscritos y

\footnotetext{
${ }^{37}$ Se trata de una conferencia sobre "los medios de comunicación y la democracia" que la Asociación pretendía organizar en la Biblioteca Nacional del Reino el 27 de septiembre de 2014.

${ }^{38}$ Tribunal administrativo Rabat, 21/03/2013, Sociedad Ecoptimis c/ El consejo de la comuna de Kenitra, No 1076.

${ }^{39}$ La parte requirente reclama ser propietaria de un inmueble de tres plantas ubicado en la Avenida Merssultan en Casablanca y que ha solicitado la autorización de demolición del antiguo edificio con objeto de reconstruirlo. Cuenta en su solicitud con el acuerdo escrito del Director regional de la cultura de la Región del Gran Casablanca ya que el edificio aún no había sido clasificado como inmueble histórico. A su vez, el presidente de la comuna de urbana de Casablanca ha autorizado la construcción de un inmueble de cinco plantas según el plano autorizado. La asociación "Casa mémoire” interviene en el procedimiento solicitando al Director general de la cultura la clasificación del citado inmueble. Éste manda un escrito al Wali de Casablanca instándole la interrupción de las obras de demolición sobre la base de la mencionada Asociación y de los habitantes del inmueble. Estimada esta solicitud, el propietario interpone un recurso administrativo ante el ministro de cultura con fecha 02/09/2013 que no tuvo respuesta.

40 Tribunal Administrativo de Rabat, 06/06/2012. Grupo de ciudadanos c/ el Presidente del Consejo comunal de Tánger.
} 
ratificados por el Estado marroquí y con la interpretación que de los mismos realizan los órganos de control creados para ello.

Esta apertura del Derecho nacional al Derecho Internacional responde a la conciencia extendida que se fundamenta en la utilidad de establecer un estándar, regional o internacional, en materia de derechos humanos. Su importancia reside en la posibilidad de trabajar conjuntamente para la consolidación de la democracia política por medio de la garantía de los derechos civiles y políticos, y el establecimiento también de una democracia social a través de la declaración y garantía de los derechos económicos, sociales y culturales.

No atender esta segunda exigencia, amén de incurrir en una merecida nulidad a imponer por parte del poder judicial, supondría una clara vulneración de las fuentes jurídicas y una clara amenaza al normal funcionamiento del Estado de Derecho.

No huelga concluir recordando que la harto conocida expresión "Estado social de Derecho” acuñada por H. HELLER en 1929 pretende llamar la atención sobre la necesidad de superar la diferencia entre la formalización jurídica de los derechos y su ejercicio efectivo por parte de todos. Cometido que requiere una doble vía de realización: de un lado cambiar el estatuto del ciudadano, pues se entiende que éste no debe ser ya sólo una persona integrada política y jurídicamente en un país, sino también económica, social y culturalmente, de otro, cambiar el estatuto jurídico del poder público, el cual, de ser meramente vigilante y represor, pasa a ser ordenador, conformador de la sociedad y promotor de la emergencia de ese nuevo ciudadano-partícipe ${ }^{41}$.

Sirva lo arriba expuesto como breve acercamiento a la faceta prestacional garantizada judicialmente en un Estado denominado como social. Pues, si bien afirmaba FORSTHOFF que puede haber Estado social con sus correspondientes funciones sin necesidad de que la Constitución lo incluya en su articulado, y añade el Profesor TORRES DEL MORAL que, con su inclusión en los preceptos constitucionales o sin ella, la política social y económica es llevada a cabo por la Administración en más o en menos según la inclinación del equipo gobernante y las posibilidades económicas del país, cabe, sin embargo, es nuestra opinión, en los tiempos que corren alegrarse por estas disposiciones normativas y por su garantía judicial que, aunque pudieron parecer prescindibles en otros tiempos, resultan del todo garantistas frente al posible vaciamiento de contenido social de esta estructura orgánica, que, hoy por hoy, asume, principalmente, la tarea de proveer de capital a un capitalismo en dificultad.

\footnotetext{
41 TORRES DEL MORAL, Antonio. “Realización del Estado Social y Constitución económica”, In El Estado Social y sus exigencias Constitucionales (Dir. TEROL BECERRA, Manuel José) pág. 29.
} 